Chapman University

Chapman University Digital Commons

Psychology Faculty Articles and Research

Psychology

$8-27-2014$

\title{
Intentions and Voluntary Actions: Reframing the Problem
}

Aaron Schurger

Chapman University, schurger@chapman.edu

Follow this and additional works at: https://digitalcommons.chapman.edu/psychology_articles

Part of the Other Psychiatry and Psychology Commons, and the Other Psychology Commons

\section{Recommended Citation}

Schurger, A. (2014) Intentions and Voluntary Actions: Reframing the Problem. Cognitive Neuroscience, 5(3-4), 213-214.

https://doi.org/10.1080/17588928.2014.950214

This Article is brought to you for free and open access by the Psychology at Chapman University Digital Commons. It has been accepted for inclusion in Psychology Faculty Articles and Research by an authorized administrator of Chapman University Digital Commons. For more information, please contactlaughtin@chapman.edu. 


\section{Intentions and Voluntary Actions: Reframing the Problem}

\section{Comments}

This is an Accepted Manuscript of an article published in Cognitive Neuroscience, volume 5, issue 3-4, in 2014, available online at DOI: 10.1080/17588928.2014.950214. It may differ slightly from the final version of record.

\section{Copyright}

Taylor \& Francis 
Aaron Schurger

Intentions and voluntary actions: reframing the problem

Comment on Nachev and Hacker

800 words max +100 word abstract

\begin{abstract}
:
Nachev and Hacker are justified in drawing our attention to the importance of conceptual clarity and coherence as these are too often overshadowed by technical sophistication and methodological rigor, which by themselves count for little. But can a process of "conceptual analysis" actually help us to avoid pitfalls, or does it merely serve to expose those pitfalls in hindsight? What is needed is a method for making scientific arguments formulaic and laying bare the implicit assumptions. We have tools for this, but not everyone uses them.
\end{abstract}

Body:

Nachev and Hacker argue that we need to engage in a process called "conceptual analysis" in order to make sure that our hypotheses are coherent. However, they do not provide us with instructions on how to wield this process. The scientific method has a set of rules and procedures that can, more or less precisely be written down. If conceptual analysis is to be useful, we have to know how to do it (unless it is more of an art than a science). Nevertheless, in the hands of these authors, conceptual analysis seems to have yielded an important notion: temporal affordance (assuming they used conceptual analysis to arrive at it).

It seems likely that temporal affordance can explain the readiness potential, and it is indeed a very powerful idea. In our research, temporal affordance takes the form of ongoing spontaneous fluctuations in brain activity whose ebb and flow continuously bias the motor system towards or away from any given action at any given time (Schurger, Sitt, \& Dehaene, 2012). These are combined with brain activity directly tied to imperatives like task instructions, demand characteristics, and drives (hunger, thirst, tiredness), that can be weak or strong relative to background fluctuations. Implemented computationally, the "stochastic decision model" can account for the shape of the readiness potential and the distribution of "waiting times" in a task where subjects initiate a movement spontaneously at a freelychosen time.

With the notion of temporal affordance in-hand, we can ask how, at the outset, would conceptual analysis have helped? It certainly helps us to see, after the fact, that it may have been a conceptual error to assume that the RP reflects "planning and preparation for movement". But was it an error vis-a-vis the conceptual landscape at the time (in 1983 or even just five years ago)? Would any amount of conceptual analysis have made any difference, or is it mainly useful for articulating our enlightened hindsight? Sometimes the ability to articulate a problem in reasoning lags behind the first-level enquiry. Our collective thinking on any given phenomenon evolves and is refined over time, and at some point we start to see our 
past mistakes and then we refine our thinking even further. Without a structured and deliberate method, can we really outdo the normal evolution of thought?

For example, in the study of intentions and their relationship to brain activity one of the main problems is that intentions are often thought of as neural phenomena rather than cognitive constructs. A priori we have no way of knowing if there even exists some class of neural events in the brain that we would be comfortable calling "intentions" (Schurger \& Uithol, 2014). This is an empirical question, and this one comes before the conceptual issue. We can try to explain the neural origins of the construct, why it is useful, what kinds of behaviors it describes, without having to explain the construct itself (Graziano \& Kastner, 2011; Schurger, 2014).

What is needed, I would argue, is a rigorous method for making scientific arguments formulaic and laying bare the implicit assumptions. We already have various simple tools that can help with this: propositional and predicate logic (all too rarely used in science), computational and theoretical modeling, and what I call the "just the facts, ma'am" approach to cognitive neuroscience.

My colleagues and I have taken the latter approach to the classic Libet (1983) paradigm, and its variants (Fried, Mukamel, \& Kreiman, 2011; Soon, Brass, Heinze, \& Haynes, 2008), and this has helped to expose some of the implicit assumptions (Schurger et al., 2012). For example, should we really expect subject's movement times to be random, as Nachev and Hacker insist? The implicit assumption here is that actions can emerge completely independently of ongoing brain activity, as if from a vacuum. Strictly speaking, this is dualist. Just about every phenomenon in nature exhibits autocorrelation in its time series - the state at time $t$ is never completely independent of the state at time $\mathrm{t}-1$ - and this is also true of the noise in brain activity (He, Zempel, Snyder, \& Raichle, 2010). If you ask a subject to produce movements at unspecified times, $\mathrm{s} /$ he is most often quite able to comply. What mechanism or strategy can the brain use to comply with this instruction? We proposed that the brain makes limited use of its own internal noise (Schurger et al., 2012). All actions must be at least partly determined by brain activity in the recent past. The interesting question is how does that relation play out, and what is its time constant? Subjects are also able to respond to questions about intentions or urges, and these responses likely carry information, perhaps relevant to making inferences about agency (which is essential for reward-base learning). What information, encoded in brain activity, do these kinds of reports carry? We can ask these kinds of questions without any prior assumptions about the nature of "intentions". 


\section{References}

Fried, I., Mukamel, R., \& Kreiman, G. (2011). Internally Generated Preactivation of Single Neurons in Human Medial Frontal Cortex Predicts Volition. Neuron, 69, 548-562.

Graziano, M.S.A., \& Kastner, S. (2011). Human consciousness and its relationship to social neuroscience: A novel hypothesis. Cognitive Neuroscience, 2(2), 98-113. doi: 10.1080/17588928.2011.565121

He, B.J., Zempel, J.M., Snyder, A.Z., \& Raichle, M.E. (2010). The Temporal Structures and Functional Significance of Scale-free Brain Activity. Neuron, 66(3), 353369.

Schurger, A. (2014). Consciousness Perceived. Science, 345(6193), 147.

Schurger, A., Sitt, J., \& Dehaene, S. (2012). An accumulator model for spontaneous neural activity prior to self-initiated movement. PNAS, 109(42), E2904E2913.

Schurger, A., \& Uithol, S. (2014). Nowhere and everywhere: the causal origin of voluntary action. Rev Phil and Psych, in press.

Soon, C.S., Brass, M., Heinze, H.-J., \& Haynes, J.-D. (2008). Unconscious determinants of free decisions in the human brain. Nat Neurosci, 11(5), 543-545. 